\title{
A Systematic Review of Obstetrical Outcomes in COVID-19 Positive Pregnant Women
}

\author{
Jiexi Teoh ${ }^{1}$, Junwen Khong ${ }^{1}$, Sharifah Shahirah Syed Hashim ${ }^{1,2}$, Nowrozy Kamar Jahan ${ }^{1}$ \\ ${ }^{1}$ Jeffrey Cheah School of Medicine and Health Sciences, Monash University Malaysia, Selangor, Malaysia \\ ${ }^{2} \mathrm{KPJ}$ Johor Specialist Hospital, Johor Bahru, Malaysia \\ Email: ^jteo0003@student.monash.edu
}

How to cite this paper: Teoh, J., Khong, J., Hashim, S.S.S. and Jahan, N.K. (2021) A Systematic Review of Obstetrical Outcomes in COVID-19 Positive Pregnant Women. Open Access Library Journal, 8: e8015. https://doi.org/10.4236/oalib.1108015

Received: September 28, 2021

Accepted: October 22, 2021

Published: October 25, 2021

Copyright () 2021 by author(s) and Open Access Library Inc.

This work is licensed under the Creative Commons Attribution International License (CC BY 4.0).

http://creativecommons.org/licenses/by/4.0/

(c) (i) Open Access

\begin{abstract}
The severe acute respiratory syndrome coronavirus 2 (SARS-CoV-2) infection has become a major public health issue worldwide since Dec 2019. With the rising number of infected cases daily, concerns have been raised to generate comprehensive and extensive evidence about the effects of COVID-19 infection during pregnancy on maternal obstetric outcomes; this would provide guidance in obstetrician clinical management to reduce maternal mortality and morbidity. The aim is to evaluate the effects of COVID-19 on pregnancy and its maternal obstetrical outcomes. We searched four databases (PubMed, Embase, Scopus and Web of Science) by using medical subject heading and keywords under the PECO concept $(\mathrm{P}=$ Pregnant woman, $\mathrm{E}=$ COVID-19 infection, $\mathrm{O}=$ Obstetric outcome). The search was performed following the Preferred Reporting Items for Systematic Reviews and Meta-Analyses (PRISMA) method to identify relevant articles based on inclusion and exclusion criteria published from January 1st 2020 to June 20th 2021. The risk of bias of the selected articles was also assessed. We found that though most pregnant women experienced mild to moderate COVID-19 symptoms, the severity development was considered multifactorial, which included issues like maternal pre-gestational comorbidity and health status. The severe form of COVID-19 was linked to an increased BMI in women. Caesarean rates were higher in the COVID-19 positive cohort, especially if the women are experiencing severe COVID-19. An increased miscarriage rate was found in women infected with COVID-19 in the first trimester of pregnancy as compared to the second trimester. The rate of preterm delivery was also elevated among pregnant women who were suffering from severe-to-critical COVID19 disease. There were reports on maternal death secondary to acute respiratory distress syndrome from COVID-19 disease, but the percentage was low. We did not find any significant link between COVID-19 and intrauterine death and infection, hypertension in pregnancy, stillbirth and post- partum
\end{abstract}


haemorrhage. COVID-19 positive pregnant women are at enhanced risk of preterm birth, obstetric complications and caesarean section delivery. This systematic review provided a comprehensive guide to obstetricians when managing a COVID-19 positive pregnancy.

\section{Subject Areas}

Infectious Disease, Obstetrics and Gynaecology

\section{Keywords}

COVID-19, SARS-CoV-2, Pregnancy, Maternal Outcome, Obstetrics Outcome

\section{Introduction}

Coronavirus Disease 19 (COVID-19), also known as Severe Acute Respiratory Syndrome Coronavirus 2 (SARS-CoV-2), is caused by a novel coronavirus that belongs to the Coronaviridae family [1] [2] [3] [4]. COVID-19 has transmitted rapidly across the globe after being first erupted in Wuhan, China during the late December of 2019; it was shortly declared as a worldwide pandemic on the March 11th of 2020 by the World Health Organization (WHO), calling attention to the immensity of the viral outbreak [1] [2] [5] [6]. Up till September 25th 2021, there is an accumulated 230 million cases worldwide, resulting in deaths of over 4.7 million [7]. Meanwhile, COVID-19 is estimated to affect 13.9 per 1000 deliveries in pregnant women [8].

While such viral outbreaks are not new in this recent two decades with the emergence of the Severe Acute Respiratory Syndrome (SARS) and the Middle East Respiratory Syndrome (MERS) in the years 2002 and 2012, respectively, COVID-19 has spread faster and caused higher mortality than that of SARS, and MERS combined, which is approximately 10,000 deaths [1] [6] [9]. Looking back in history, the pregnant population has been seriously affected by various adverse pregnancy events following the outbreaks of SARS and MERS. Also, the severity of a respiratory infection is likely to be increased for a pregnant woman due to ineffective airway clearance secondary to anatomical and physiological changes during pregnancy [10]. Considering that the COVID-19 virus is from the same human coronavirus family as the previous SARS-CoV-1 and MERS$\mathrm{CoV}$ outbreaks, there are emerging worries that the pregnant population who are infected with COVID-19 will have potential similar adverse outcomes as the previous two outbreaks [1] [11] [12]. This review paper aims to appraise the currently available evidence through a systematic approach to identify the factors influencing the maternal obstetrics outcomes of COVID-19 infected pregnant women. The review findings will contribute to developing a comprehensive maternal care modality and appropriate preventive strategies for COVID-19 related pregnancy complications. 


\section{Methods}

\subsection{Search Strategy}

We conducted this systematic review in the databases including PubMed, Embase, Scopus and Web of Science. The primary reviewers' institution subscribes these four electronic databases; hence, it was convenient to get access to full-text resources. The search was performed from January 1st 2020 to June 20th 2021 following the Preferred Reporting Items for Systematic Reviews and MetaAnalyses (PRISMA) method to identify relevant articles on COVID-19 infected pregnancies and maternal outcomes. We searched all databases using keywords and $\mathrm{MeSH}$ terms related to COVID-19 disease (Table 1), pregnant women and maternal outcomes. We used search string across all databases, which included [(“Covid" OR "SARS-CoV-2" OR "Covid-19" OR "Coronavirus disease 2019" OR "2019-nCoV”) AND ("Pregnancy" OR "Pregnant" OR "Pregnant woman") AND ("Maternal outcomes" OR "Pregnancy outcomes" OR "Obstetrics outcomes")]. To refine the search results further, we also applied a filter including "only articles in English language and females with age ranging from 19 to 44 years as the research population".

\subsection{Selection Criteria}

1) Inclusion criteria: Following inclusion criteria were considered before including any study in this review:

- Study types: Cohort studies, randomized controlled trials, database analysis;

- Study sample size: More than 150 COVID-19 infected pregnant women;

- Reported outcomes of COVID-19 infected pregnancies;

- If the full text is available;

- English language.

2) Exclusion criteria: Following criteria were considered before excluding

Table 1. Keywords and subject headings according to PECO concept.

\begin{tabular}{|c|c|c|}
\hline Concept & $\begin{array}{l}\text { Subject Headings } \\
(\mathrm{MeSH} / \text { Emtree })\end{array}$ & Keywords/Entry Terms \\
\hline $\begin{array}{l}\text { Population: } \\
\text { Pregnant women }\end{array}$ & $\begin{array}{l}\text { - } \text { Pregnant women } \\
\text { - } \text { Pregnancy } \\
\text { - Gravidity }\end{array}$ & $\begin{array}{l}\text { - } \text { Pregnant woman } \\
\text { - } \text { Pregnancy } \\
\text { - Gestation } \\
\text { - Gravidity } \\
\text { - } \text { Childbearing }\end{array}$ \\
\hline Exposure: COVID-19 & $\begin{array}{ll}\text { - } & \text { COVID-19 } \\
\text { - } & \text { SARS-CoV-2 } \\
\text { - } & \text { Coronavirus disease } 2019 \\
\text { - } & \text { Severe acute respiratory } \\
& \text { syndrome coronavirus } 2\end{array}$ & $\begin{array}{ll}\text { - } & \text { COVID-19 } \\
\text { - } & \text { 2019-nCoV } \\
\text { - } & 2019 \text { Novel Coronavirus } \\
\text { - } & \text { Coronavirus Disease } 2019 \\
\text { - } & \text { SARS Coronavirus } 2\end{array}$ \\
\hline $\begin{array}{l}\text { Outcome: Obstetrics } \\
\text { outcome }\end{array}$ & $\begin{array}{ll}\text { - } & \text { Pregnancy outcome } \\
\text { - } & \text { Delivery, Obstetric } \\
\text { - } & \text { Birth }\end{array}$ & $\begin{array}{l}\text { - Maternal outcome } \\
\text { - Pregnancy outcome } \\
\text { - Birth } \\
\text { - Perinatal outcome } \\
\text { - Obstetric delivery } \\
\text { - Labour outcome }\end{array}$ \\
\hline
\end{tabular}


any study from this review:

- Study types: Review articles, case reports, case series, protocol papers, crosssectional studies;

- Study sample size: Less than 150 COVID-19 infected pregnant women;

- Occurring of COVID-19 infection before the pregnant period;

- If the specific outcomes of pregnancy are not mentioned;

- If the language is not in English;

- Incomplete trials or duplicate publications of the same study that yield similar results.

\subsection{Screening}

We aimed to screen the articles published from January 1st 2020 onwards. Initially, we identified 2389 articles from the four databases: Pubmed (448 articles), Embase (867 articles), Scopus (768 articles), and Web of Science (306 articles). Thereafter, we exported all articles to the citation manager Endnote and identified the duplicates using the EndNote software before removing them. Two reviewers simultaneously screened all the potential articles by title and abstract based on the inclusion and exclusion criteria. Lastly, we selected 13 articles (Figure 1) after full-text screening and included those for data extraction under this review. Out of 13 articles, the majority articles were available in PubMed (Table 2).

\subsection{Data Extraction}

Two primary reviewers (JT and $\mathrm{JK}^{1}$ ) used a standardized form, which included: study design, sample size, main study findings and conclusion, to extract all the potential data independently from 13 finally selected articles. Thereafter, they compared their individual data and reached a consensus before including the data for analysis by NVivo software. They invited the 3rd reviewer, either SSSH or $\mathrm{NKJ}^{2}$, when they could not resolve any discrepancies.

\subsection{Quality Assessment}

We assessed the quality of each study using the Newcastle-Ottawa Scale (NOS) (Table 3), which is a tool to assess the quality of both cohort and case-control studies included in a systematic review. We selected this NOS tool as most of our included studies were cohort studies, either prospective or retrospective. The NOS tool has three parameters: selection $=4$, comparability $=2$ and outcome $=$ 3 ; based on that we conducted the quality assessment of all 13 studies. Two primary reviewers conducted the quality assessment independently and invited the third reviewer to resolve any disagreement.

\section{Results}

We identified 7030 pregnant women with COVID-19 positive status from the ${ }^{1}$ JT: Jiexi Teoh; JK: Junwen Khong.

${ }^{2} \mathrm{SSSH}$ : Sharifah Shahirah Syed Hashim; NKJ: Nowrozy Kamar Jahan. 

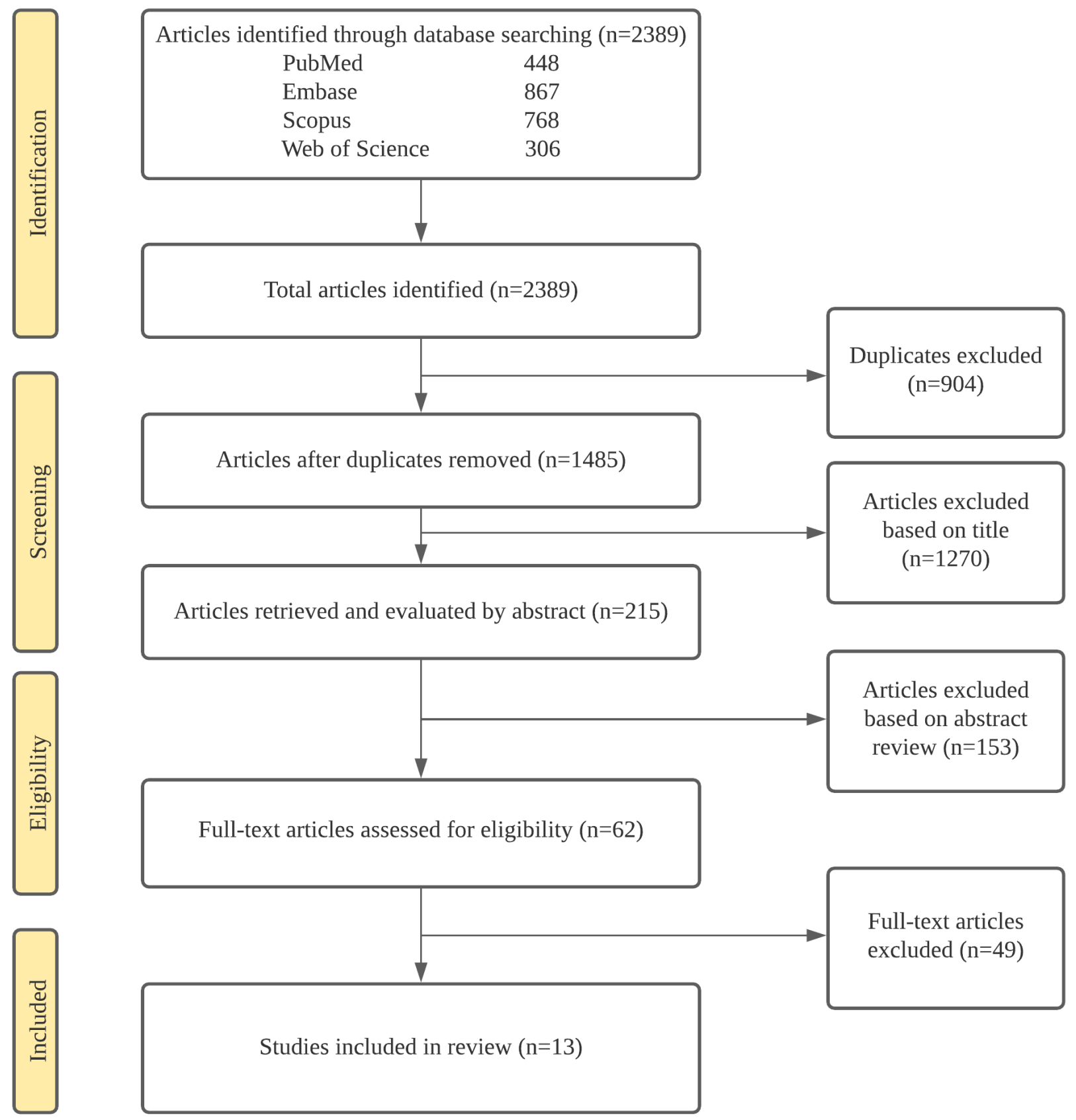

Figure 1. PRISMA chart used for the selection of articles.

cohort studies conducted in different parts of the world, including the USA, UK, Europe like Spain, South America like Peru, Chili and Middle-east countries like Kuwait and Saudi-Arabia [13]-[25]. The COVID-19 positive status was confirmed among most of the pregnant women (90\% and above) by laboratory SARS-CoV-2 real-time polymerase chain reaction (RT-PCR) assay, SARS-CoV-2 antibody testing, or radiological findings. In the INTERCOVID Multinational Cohort Study, a small proportion (7.1\%) of pregnant women was clinically diagnosed with COVID-19 without laboratory confirmation [24]. The main study findings and conclusion are summarized in Table 4. 
Table 2. Selected articles and their source.

\begin{tabular}{ccc}
\hline Author & Year of publication & Database \\
\hline Al-Matary et al. & 2021 & PubMed \\
Ayed et al. & 2020 & PubMed \\
Crovetto et al. & 2021 & Embase \\
Cruz-Melguizo et al. & 2021 & Scopus \\
Haye et al. & 2021 & Web of Science \\
Khoury et al. & 2020 & PubMed \\
Lokken et al. & 2021 & Embase \\
Martinez-Perez et al. & 2021 & PubMed \\
Metz et al. & 2021 & PubMed \\
Saccone et al. & 2021 & Web of Science \\
Taya et al. & 2020 & Web of Science \\
Villar et al. & 2021 & Embase \\
Vousden et al. & 2021 & PubMed \\
\hline
\end{tabular}

\subsection{Socio-Demographic Status}

The maternal age ranged from 18 to 49 years [13]-[20] [22] [23] [25]. With regards to the median age, the range was from 28 to 32 years [13] [14] [18] [19]. Seven studies included the ethnic backgrounds of the patients [15] [16] [18] [19] [20] [21] [25]. Non-Hispanic whites or Hispanics made up the majority (up to 64.2\%) of the research population [15] [16] [18] [19] [20] [21] [25]. Other ethnicities included were non-Hispanic Blacks, Asians, and others [15] [16] [18] [19] [20] [21] [25]. Low socioeconomic status, defined as having no educational background, no employment history or being unemployed for more than two years, was found to be $33.3 \%$ among the COVID-19 positive pregnant women in one study [15].

\subsection{Pregnancy Characteristics}

The percentage of nulliparous women ranged from $19.5 \%$ to $53 \%$ [14] [15] [16] [17] [18] [20], while up to $80.5 \%$ of women were multiparous [14] [17] [25]. In one study, multiparity was associated with higher rates of moderate and severe COVID-19 as compared to nulliparous pregnant women who were infected with the virus ( $87.5 \%$ vs. $12.5 \% ; 62.5 \%$ vs. $37.5 \%)$ [23]. Most of the pregnancy was a singleton, and only $1.1 \%$ to $2.5 \%$ were of multiple pregnancies [14] [16] [17] [18] [20] [23] [25].

\subsection{Pre-Existing Comorbidities}

Obesity, defined as body mass index (BMI) more than $30 \mathrm{~kg} / \mathrm{m}^{2}$, was the most common pre-gestational comorbidities identified, with the highest prevalence of 55.1\% [13] [15]-[22] [24] [25]. Pregnant women who were overweight or obese 
Table 3. Risk of bias assessment of the selected articles.

\begin{tabular}{|c|c|c|c|c|c|c|c|c|c|c|}
\hline \multirow[b]{2}{*}{$\begin{array}{l}\text { First author; } \\
\quad \text { Year }\end{array}$} & \multicolumn{4}{|c|}{ Selection } & \multicolumn{2}{|c|}{ Comparability } & \multicolumn{3}{|c|}{ Outcome } & \multirow[t]{2}{*}{ Total } \\
\hline & 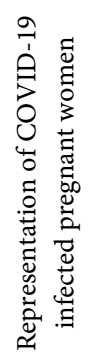 & 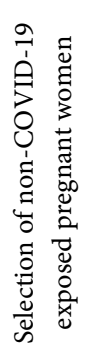 & 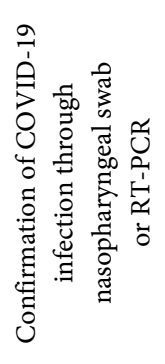 & 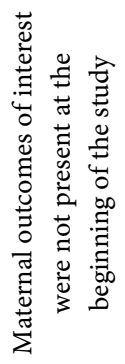 & 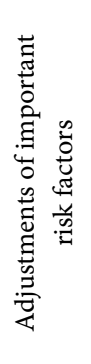 & 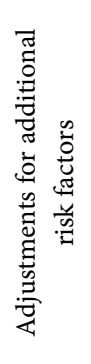 & 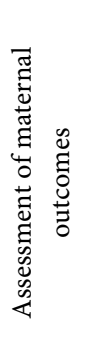 & 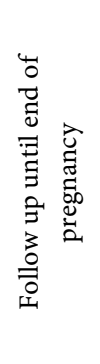 & 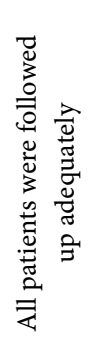 & \\
\hline $\begin{array}{l}\text { Al-Matary et al:; } \\
2021\end{array}$ & 众 & & $\hat{\imath}$ & 5 & & & & 市 & & 7 \\
\hline Ayed et al:; 2020 & t & 全 & t & $\hat{\imath}$ & & & t & $\hat{\imath}$ & tr & 9 \\
\hline $\begin{array}{l}\text { Crovetto et al.; } \\
2021\end{array}$ & 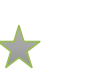 & 知 & r & 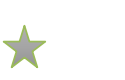 & & & 㟀 & & & 6 \\
\hline $\begin{array}{l}\text { Cruz-Melguizo } \\
\text { et al:; } 2021\end{array}$ & 苁 & 竹 & & 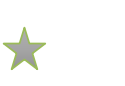 & & & & $\boldsymbol{N}$ & & 9 \\
\hline $\begin{array}{l}\text { Khoury et al:; } \\
2020\end{array}$ & $\hat{n}$ & & N & 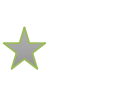 & & & 全 & & & 7 \\
\hline $\begin{array}{l}\text { Lokken et al:; } \\
2021\end{array}$ & 人 & 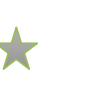 & & $=$ & & & & & & 9 \\
\hline $\begin{array}{l}\text { Martinez-Perez } \\
\text { et al:; } 2021\end{array}$ & N & h & & & & & 个 & 1 & & 9 \\
\hline Metz et al.; 2021 & N & & $\hat{\imath}$ & 今 & & & $\hat{\imath}$ & $\hat{h}$ & & 8 \\
\hline Haye et al.; 2021 & 全 & & $\hat{\imath}$ & 各 & & & 市 & & 人 & 7 \\
\hline $\begin{array}{l}\text { Saccone et al:; } \\
2021\end{array}$ & 众 & N & N & 人 & & & N & 人 & $x$ & 9 \\
\hline Taya et al:; 2020 & 人 & & $\hat{\imath}$ & 5 & & & $\hat{\imath}$ & & & 6 \\
\hline Villar et al:; 2021 & 众 & t & $\hat{\imath}$ & $\hat{\imath}$ & & & $\hat{x}$ & & t & 8 \\
\hline $\begin{array}{l}\text { Vousden et al:; } \\
2021\end{array}$ & 负 & 人 & 人 & 久 & 7 & & 乐 & 市 & 六 & 9 \\
\hline
\end{tabular}

were more likely to be hospitalized due to symptomatic COVID-19 and are at risk of higher maternal morbidity and mortality [24] [25]. In the group of patients admitted for critical-severe COVID-19, there was a higher proportion of women with a BMI of $30 \mathrm{~kg} / \mathrm{m}^{2}$ or more (58.4\%) [21]. Pre-pregnancy asthma had affected up to $8.3 \%$ of women [13] [14] [15] [16] [17] [19] [20] [25]. Chronic lung disease was only found in $0.2 \%$ to $0.4 \%$ of COVID-19 infected pregnant women [13] [16] [20]. While most of the infected pregnant women were nonsmokers, up to $14.2 \%$ of them had a smoking history [15] [16] [18] [20] [21] [22] [25].

We also found that $1.2 \%$ to $4.6 \%$ of pregnant women had chronic hypertension [13] [15] [16] [17] [19] [20] [25]. When compared to non-hospitalized pregnant women with COVID-19 disease, it was found that those with obesity, 
Table 4. List of selected articles which are included in review with the main findings and conclusion.

\begin{tabular}{|c|c|c|c|c|}
\hline $\begin{array}{c}\text { Author; Study country; } \\
\text { Year of Publication } \\
\text { [Reference number] }\end{array}$ & Type of study & $\begin{array}{l}\text { Sample } \\
\text { size }\end{array}$ & Main findings & Conclusion \\
\hline $\begin{array}{l}\text { Al-Matary et al:; } \\
\text { Saudi Arabia; } 2021 \text { [13] }\end{array}$ & Cohort study & 288 & $\begin{array}{l}\text { A majority of pregnant women were symptomatic } \\
\text { with cough being the most frequent COVID-19 } \\
\text { symptom. } \\
\text { - Caesarean section made up } 35.8 \% \text { of the deliveries. } \\
\text { - Prematurity (15.5\%) was the most common } \\
\text { adverse pregnancy outcome, followed by foetal } \\
\text { distress ( } 6.5 \%) \text { and pre-eclampsia (2.0\%). } \\
\text { - Less than half (43\%) of neonates of COVID- } 19 \\
\text { positive mothers were admitted into the neonatal } \\
\text { intensive care unit (NICU) for respiratory support. } \\
\text { None of the newborns were positive for } \\
\text { COVID-19 infection. }\end{array}$ & $\begin{array}{l}\text { The majority of the } \\
\text { pregnant women with } \\
\text { COVID-19 infection } \\
\text { experienced mild or } \\
\text { moderate disease } \\
\text { symptoms. } \\
\text { - No evidence was found } \\
\text { to suggest vertical } \\
\text { transmission of } \\
\text { COVID-19 infection } \\
\text { from mothers to their } \\
\text { newborns. }\end{array}$ \\
\hline $\begin{array}{l}\text { Ayed et al:; Kuwait; } \\
2020 \text { [14] }\end{array}$ & Cohort study & 185 & $\begin{array}{l}\text { The majority of the pregnant women experienced } \\
\text { mild symptoms of COVID-19, with fever (58.6\%) } \\
\text { being the most common presenting symptom. } \\
\text { 1.6\% of the pregnant women had a miscarriage } \\
\text { and } 8.6 \% \text { had ongoing pregnancies, while } \\
89 \% \text { had a live birth. } \\
\text { - The median gestational age at birth for newborns } \\
\text { was } 38 \text { (IQR: } 36 \text { - 39) weeks. } \\
\text { Only } 2 \text { newborns were tested positive for } \\
\text { COVID-19 on day } 5 \text { by nasopharyngeal } \\
\text { swab testing. }\end{array}$ & $\begin{array}{l}\text { Most pregnant women } \\
\text { infected with } \\
\text { COVID-19 had mild } \\
\text { symptoms. } \\
\text { While there is a } \\
\text { possibility of } \\
\text { mother-to-child vertical } \\
\text { transmission when a } \\
\text { pregnant woman is } \\
\text { infected with } \\
\text { COVID-19, it } \\
\text { may not lead to } \\
\text { unfavourable maternal } \\
\text { and neonatal outcomes. }\end{array}$ \\
\hline $\begin{array}{l}\text { Crovetto et al.; } \\
\text { Spain; } 2021 \text { [15] }\end{array}$ & Cohort study & 317 & $\begin{array}{l}\text { A majority of the COVID-19 positive pregnant } \\
\text { women were asymptomatic }(68.5 \%) \text { or had mild } \\
\text { symptoms ( } 29.3 \%) \text {. } \\
\text { Symptomatic women had higher rates of preterm } \\
\text { delivery ( } 16.9 \% \text { vs } 7.2 \% ; \mathrm{P}=0.03) \text { and intrapartum } \\
\text { foetal distress }(19.2 \% \text { vs } 9.1 \%, \mathrm{P}=0.004) \text { when } \\
\text { compared to non-infected women, however, the } \\
\text { rates for asymptomatic women were similar to } \\
\text { those of non-infected cases. } \\
\text { None of the newborns of COVID-19 positive } \\
\text { mothers had anti-SARS-CoV-2 IgM/IgA in cord } \\
\text { blood. }\end{array}$ & $\begin{array}{l}\text { - In general, there was } \\
\text { little difference in the } \\
\text { rates of pregnancy } \\
\text { complications between } \\
\text { infected and } \\
\text { non-infected women. } \\
\text { - An increase in preterm } \\
\text { delivery and } \\
\text { intrapartum foetal } \\
\text { distress was associated } \\
\text { with symptomatic } \\
\text { COVID-19 infection. }\end{array}$ \\
\hline $\begin{array}{l}\text { Cruz-Melguizo et al:; } \\
\text { Spain; } 2021 \text { [16] }\end{array}$ & Cohort study & 1347 & $\begin{array}{l}\text { There were higher rates of premature rupture of } \\
\text { membranes, venous thrombotic events and severe } \\
\text { pre-eclampsia incidence in COVID-19 positive } \\
\text { pregnancies compared to non-infected } \\
\text { pregnancies, which could have been overestimated } \\
\text { in the infected cohort due to the shared clinical } \\
\text { signs of the hypertensive disorders and COVID-19. } \\
\text { More infected patients delivered preterm mainly } \\
\text { due to a higher rate of iatrogenic preterm births. } \\
\text { Prematurity in COVID-19 affected pregnancies } \\
\text { results from a predisposition to terminate the } \\
\text { pregnancy due to maternal disease. }\end{array}$ & $\begin{array}{l}\text { Pregnant women with } \\
\text { COVID-19 are at risk } \\
\text { of preterm deliveries, } \\
\text { mainly due to } \\
\text { iatrogenic deliveries } \\
\text { secondary to } \\
\text { pneumonia and/or } \\
\text { pre-eclampsia. } \\
\text { A higher proportion } \\
\text { of infected women } \\
\text { reported venous } \\
\text { thromboembolism and } \\
\text { disseminated } \\
\text { intravascular } \\
\text { coagulation. }\end{array}$ \\
\hline
\end{tabular}


Haye et al:; Chile, 2021 [17]

Cohort study 458

Khoury et al:; USA; 2020 [18]

Lokken et al:;

USA; 2021 [19]

Martinez-Perez et al:; $2021[20]$

Metz et al:; USA; 2021 [21]

Cohort study $\quad 241$

Cohort study $\quad 246$

Cohort study
- A majority (74.4\%) of the COVID-19 positive women presented with mild symptoms and $25.5 \%$ of them experienced severe COVID-19 symptoms.

- $5.6 \%$ women were admitted into the ICU and $2.8 \%$ of them required mechanical ventilation.

- Adverse maternal outcomes were linked to severe COVID-19 presentation, infection over 24 weeks, and comorbidities.

- $16.5 \%$ of the deliveries were preterm.

Cohort study $\quad 240$

1219

- A majority of women were asymptomatic for COVID-19 at the time of admission.

- $52.4 \%$ of women with severe and $91.7 \%$ with critical COVID-19 underwent caesarean delivery.

- The rate of preterm delivery was $14.6 \%$.

- Body mass index (BMI) of 30 or higher was associated with COVID-19 severity $(\mathrm{P}=0.001)$.

- $97.5 \%$ of newborns were tested negative for SARS-CoV-2 infection immediately after birth.

- Disease severity was linked to comorbidities or underlying conditions including asthma, hypertension, type 2 diabetes mellitus, autoimmune disease, and class III obesity.

- The case fatality for COVID-19 was 13.6-fold higher in the pregnant population compared to individuals of a similar age.

- Higher rates of preterm delivery were observed in women with severe or critical COVID-19 compared to women who had recovered from the infection.

- Being SARS-CoV-2 positive increased the odds of preterm deliveries compared to non-infected mothers.

- Infected women more commonly reported iatrogenic preterm births, but the occurrence of spontaneous preterm deliveries was similar statistically.

- There was an increased risk of premature rupture of membranes at term and neonatal intensive care unit admissions in positive mothers.

- Disease severity was associated with older mean age, higher median body-mass-index, and pre-existing medical comorbidities.

- Women with severe-critical COVID-19 had an increased risk of adverse perinatal outcomes like caesarean birth, hypertensive disorders of
- Maternal compromise resulted from women with severe COVID-19 and the occurrence of disease in the second half of the pregnancy.

- The high perinatal morbidity and mortality in severe COVID-19 positive women warrants attention.

- Outpatient management was safe for mild cases. pregnancy and preterm deliveries compared to asymptomatic women.

- Compared with asymptomatic patients, mild-moderate COVID-19 was not associated with adverse perinatal outcomes.
- Obesity was associated with COVID-19 severity.

- Disease severity was associated with higher rates of caesarean and preterm deliveries.

- Pregnant women are at risk of developing severe or critical disease COVID-19 infection, compared to non-pregnant adults of similar age, as well as preterm birth.

- Pregnant women who were COVID-19 positive demonstrated more infection-related obstetric morbidity.

- Pregnant women with severe-critical COVID-19, but not those with COVID-19 were at an increased risk of perinatal complications compared with asymptomatic pregnant patients. and mortality from mild-moderate 
Saccone et al:; Multinational (22 countries); 2020 [22]

Taya et al.; Peru; 2020 [23]

Villar et al:;

Multinational (18 countries); 2021 [24]

Vousden et al:; UK; 2021 [25]
Cohort study $\quad 388$

Cohort study $\quad 247$

Cohort study $\quad 706$

Cohort study $\quad 1148$
- $12.1 \%$ of women with a positive SARS-CoV-2 status had composite adverse maternal outcomes; $11.1 \%$ were admitted to the ICU, $9.3 \%$ required mechanical ventilation and $0.8 \%$ died.

- Excluding the 122 women who were still pregnant at the time of data analysis, six had miscarriage, three had termination of pregnancy, six had stillbirth and 251 delivered a liveborn infant.

- The preterm delivery rate was $26.3 \%$.

- Only one (0.4\%) infant was found to be SARS-CoV-2 positive on RT-PCR.

- $83 \%$ of the SARS-CoV-2 positive pregnancies were asymptomatic, with only $3.2 \%$ of them being severe.

- Rates for caesarean deliveries were high (60\%), while vaginal delivery rates had doubled over time.

- Severe cases had higher rates of caesarean section and iatrogenic preterm delivery.

- Women infected with COVID-19 were at a higher risk for pre-eclampsia/eclampsia, severe infections, intensive care unit admission, maternal mortality, preterm birth, severe neonatal morbidity index, and severe perinatal morbidity and mortality index.

- Any duration of fever and shortness of breath was associated with increased risk of severe maternal and neonatal complications

- $13 \%$ of the neonates of COVID-19 positive mothers tested positive.

- Caesarean deliveries but not breastfeeding was linked to an increased risk for neonatal test positivity.

- Women who were overweight or obese, of Black, Asian or other minority ethnic group, and having a relevant medical comorbidity, were more likely to be symptomatic for SARS-CoV-2 requiring hospitalisation, when compared to non-infected pregnant women.

- Regardless of symptom status, there were increased rates of caesarean deliveries and neonatal unit admission.
- SARS-CoV-2 infection during pregnancy was associated with a low maternal mortality rate, but an $11.1 \%$ rate of ICU admission.

- The risk of vertical transmission may be negligible.

- There is a higher possibility of caesarean and iatrogenic preterm deliveries in severe cases.

- COVID-19 infection was not found to be linked to perinatal complications.

- When comparing pregnant women with and without COVID-19 diagnosis, a positive infection status was linked with increases in severe maternal morbidity and mortality and neonatal complications.

- Factors that increase the risk of symptomatic and asymptomatic SARS-CoV-2 in pregnancy have been identified.

- The majority of women do not experience severe complications of SARS-CoV-2 in pregnancy.

asthma, and hypertension were more likely to be hospitalized due to COVID-19 symptoms or concerns ( $21.1 \%$ vs. $6.3 \%, p=0.01 ; 20.8 \%$ vs. $6.9 \%, p=0.02 ; 20.8 \%$ vs. $2.8 \%, \mathrm{p}<0.001)$ [19]. The prevalence of cardiovascular diseases before pregnancy (excluding hypertension) was found to be low (0.3\% to 2\%) [13] [16] [20] [25].

Pre-gestational type 2 diabetes mellitus was also uncommon among the infected pregnant women (0.5\% to 5.4\%) [13] [14] [15] [16] [17] [19] [20] [25]. 
However, in the study by Metz et al., critical or severe COVID-19 diseases were more likely to develop in pregnant women with pre-existing asthma, chronic obstructive pulmonary disease, chronic hypertension, and diabetes [21].

Other comorbidities such as thyroid dysfunctions, liver and renal diseases, haematological diseases, autoimmune diseases, and psychological disorders were infrequently reported [13] [14] [16] [17] [19] [20] [21].

\subsection{Exposure}

The median gestational age at maternal diagnosis of COVID-19 ranged from 29 to 38 weeks [13] [14] [21]. Half or more (51.3\% to 56.3\%) of the SARS-CoV-2 diagnoses were confirmed during the third trimester [14] [19]. The rates of asymptomatic and symptomatic pregnant women showed a huge variability among the studies, ranging from $22.9 \%$ to $88.6 \%$ and $11.4 \%$ to $88.6 \%$ for both categories, respectively [13]-[25]. The commonly reported symptoms were fever, cough, sore throat and shortness of breath [13] [14] [18] [20] [21] [22] [23] [24]. It was found that pregnant women presenting with any duration of fever and dyspnoea were more likely to develop severe maternal complications (RR: 2.56; 95\% CI: 1.92 - 3.40) [24].

Most symptomatic pregnant mothers experienced mild to moderate COVID-19 disease, only requiring oxygen supplementation through nasal cannula or face mask, or none at all [13] [16] [18] [19] [20] [22] [23]. Severe COVID-19 disease occurred in $3.2 \%$ to $26.1 \%$, while only $1.7 \%$ to $4 \%$ of pregnant women developed critical COVID-19 disease [16]-[21]. Among the severe and critical COVID-19 group, maternal hypoxia and acute respiratory failure were reported up to $61 \%$ and $67 \%$, respectively [21].

Mechanical ventilation was required in $2.1 \%$ to $16.7 \%$ of the symptomatic pregnant population [13] [17] [19] [22]. Lymphopenia, elevated liver enzymes (ALT, AST), elevated CRP and procalcitonin, and chest imaging abnormalities consistent with COVID-19 pneumonia were the frequently encountered investigation findings [13] [14] [18]-[23]. Mothers of positive COVID-19 were commonly treated with antibiotics, antivirals, low molecular weight heparin (LMWH) and corticosteroids [13] [14] [21] [25].

\subsection{Outcomes}

We found that $1.4 \%$ to $4.6 \%$ of the pregnant mothers experienced a pregnancy loss before 24 weeks of gestation [14] [15] [17] [22] [25], and 19.4\% of pregnancy loss occurred in mothers who were infected in the first-trimester [22]. In terms of hypertensive disorders during pregnancy, which includes gestational hypertension, pre-eclampsia, eclampsia and Haemolysis, Elevated Liver enzyme and Low Platelet Syndrome (HELLP), the incidence rate was from 1.3\% to $40.4 \%$ [13] [14] [15] [16] [17] [19] [20] [21] [24] [25]. The risk of developing pre-eclampsia or eclampsia was increased for pregnant women infected with COVID-19 disease (RR: 1.76, 95\% CI: 1.27 - 2.43), even for the asymptomatic 
mothers (RR: 1.63, 95\% CI: 1.01 - 2.63) [24]. It was also found that $89.5 \%$ of new-onset gestational hypertensive disorders were detected at or after the diagnosis of COVID-19 infection [19]. Pregnant women with gestational diabetes ranged from $5.24 \%$ to $11.0 \%$ [14] [16] [17] [19] [20] [25].

In general, $1.1 \%$ to $11.1 \%$ of women were admitted to the intensive care unit (ICU) [13]-[25]. Pregnant women diagnosed with COVID-19 infection had a higher tendency for ICU admission as compared with non-infected mothers (RR: 5.04, 95\% CI: 3.13 - 8.10) [24]. Among the COVID-19 positive pregnant women, those who were symptomatic, especially with a severe form of the disease, were at a higher risk of ICU admission [15] [17] [22]. Maternal deaths were uncommon, with mortality rates of no more than $1.6 \%$. However, despite a wide range of confidence intervals, it was worth noting that pregnant women with COVID-19 were at a 22 times higher risk of dying (RR: 22.3; 95\% CI: 2.88 - 172) [24].

The prevalence of preterm birth among pregnant women diagnosed with COVID-19 ranged from $9.7 \%$ to $26.6 \%$ (Table 5) [13]-[25]. Comparing symptomatic COVID-19 positive mothers to those without the infection, there was a 10-fold increased risk of preterm births in the infected women (OR: 11.43, 95\% CI: 5.07 - 25.75) [25]. However, the rates of preterm births were similar among the asymptomatic maternal COVID-19 infection and non-infected pregnant women [15]. Medically indicated or iatrogenic preterm labour was more likely to occur in COVID-19 positive mothers (RR: 1.97, 95\% CI: 1.56 - 2.51) [24]. Up to $83 \%$ of the iatrogenic preterm births were indicated due to COVID-19 symptoms

Table 5. The rates of preterm birth among COVID-19 positive mothers across different studies and their characteristics.

\begin{tabular}{|c|c|c|c|}
\hline $\begin{array}{c}\text { Author; } \\
\text { Year of Publication }\end{array}$ & $\begin{array}{l}\text { Preterm birth } \\
\text { (General) }\end{array}$ & $\begin{array}{c}\text { Medically } \\
\text { indicated/Iatrogenic }\end{array}$ & Spontaneous \\
\hline Al-Matary et al.; 2021 & 15.5 & NA & NA \\
\hline Ayed et al:; 2020 & 26.6 & 1.2 & NA \\
\hline Crovetto et al.; 2021 & 11.4 & NA & NA \\
\hline Cruz-Melguizo et al:; 2021 & 11.1 & 47.7 & 38.9 \\
\hline Haye et al:; 2021 & 16.5 & NA & NA \\
\hline Khoury et al:; 2020 & 14.6 & NA & NA \\
\hline Lokken et al:; 2021 & 9.7 & NA & NA \\
\hline Martinez-Perez et al.; 2021 & 13.8 & 7.7 & 6.1 \\
\hline Metz et al:; 2021 & 16.7 & 10.6 & 6.2 \\
\hline Saccone et al:; 2020 & 26.3 & 80.0 & 20.0 \\
\hline Taya et al:; 2020 & 18.5 & 8.8 & NA \\
\hline Villar et al:; 2021 & 22.5 & 18.8 & 3.8 \\
\hline Vousden et al.; 2021 & 18.3 & 14 & 4 \\
\hline
\end{tabular}

${ }^{\star}$ All figures were given in percentage; ${ }^{\star N A}$ : Not available. 
or pneumonia [16] [20] [23]. Among them, up to $63.6 \%$ of the cases were from mothers with severe or critical COVID-19 disease [18] [19]. In another study, more than half of the women with severe COVID-19 delivered preterm, all of them being iatrogenic [23].

On the other hand, non-COVID-related indications for preterm deliveries that were commonly reported in the COVID-19 positive pregnant women were as follows: hypertensive disorders of pregnancy (7\% - 33\%), stillbirth (16\%), preterm prelabour rupture of membranes (PPROM) (13\%), spontaneous rupture of membranes (20.0\%), small for gestational age (SGA) (15.5\%), and foetal distress (13.2\%) [16] [20] [21] [22] [24].

Vaginal birth accounted for $41.7 \%$ to $64.2 \%$ of all deliveries [13] [14] [16] [17] [18] [23] [25]. The overall caesarean section rates among the COVID-19 positive cohort ranged from $22.4 \%$ to $54.2 \%$ [13]-[25]. We observed a trend of Caesarean section for COVID-19 positive mothers who were symptomatic or experiencing severe forms of the disease [16] [17] [18] [21] [23] [25]. Vousden et al. showed a statistically significant increased risk of caesarean section delivery, as high as 1.5 -times, among pregnant women with symptomatic COVID-19 compared to those who were asymptomatic (OR $=1.51,95 \% \mathrm{CI}=1.11-2.06)$ [25]. Severe and critical COVID-19 further increased the risk of caesarean section (RR: 1.62, 95\% CI: $1.1-2.3, \mathrm{p}=0.01$; RR: 2.8, 95\% CI: $2.0-3.8, \mathrm{p}<0.001)$ [18]. Elective and maternal requests for caesarean delivery were as high as $44.3 \%$, while other indications included hypertensive disorder of pregnancy, malpresentation, foetal distress, placental abnormalities and failed induction of labour [14] [16] [20] [21] [23] [25].

The incidence of perinatal losses (stillbirth and foetal death) remained low, accounting for $0.6 \%$ to $8.4 \%$ of deliveries [13]-[23] [25]. Up to $12.9 \%$ of neonates born to mothers with COVID-19 were tested positive for the disease [13] [14] [17]-[25]. Nearly half of the newborns were found to have IgG antibodies alone without any presentation of infection during the neonatal period [15].

\section{Discussion}

Obesity has always been a huge concern for women in the reproductive age range, and it is as common as affecting one-third of the pregnant women population in the West [26] [27]. Maternal obesity plays a role in disrupting maternal metabolism and predisposes pregnant women to a higher risk of gestational diabetes and pre-eclampsia, which can lead to adverse pregnancy outcomes such as preterm birth and perinatal mortality [26]. In our review, a BMI of more than $30 \mathrm{~kg} / \mathrm{m}^{2}$ was the most common pre-gestational comorbidities in the COVID-19 positive women. It was found that a higher proportion of pregnant women with severe COVID-19 disease were obese. A comparison with other studies identified a similar link between obesity and severe COVID-19 presentation among pregnant mothers [28] [29] [30].

There was a variability in the percentage of asymptomatic COVID-19 preg- 
nant women in our systematic review. In part, the high proportion of COVID-19 pregnancies that were asymptomatic can be attributed to the universal screening of all pregnant women who were admitted to the hospital for deliveries [31]. We also observed that half or more (51.3\% to 56.3\%) of the COVID-19 diagnoses were made during the third trimester, which can be explained by the practice of conducting testing near term [31]. This situation has contributed to a higher proportion of women being tested positive in the 3rd trimester rather than in earlier stages of pregnancy, especially if they were asymptomatic.

Most symptomatic COVID-19 pregnancies in our study reported mild-tomoderate symptoms. This finding was consistent with the World Health Organization (WHO) report, which stated that pregnant women are not more vulnerable to a severe illness course [32]. Albeit the similar vulnerability between pregnant women and those of a similar reproductive age in terms of COVID-19 severity, the same cannot apply if the pregnancy is complicated with pulmonary comorbidities [aOR 4.3, 95\% CI: 1.9 - 9.5], hypertensive disorders [aOR 2.7, 95\% CI: 1.0 - 7.0] and diabetes [aOR2.2, 95\% CI: 1.1 - 4.5] [33].

In this review, we did not identify any mention of the mutated SARS-CoV-2 strains and their impact on the COVID-19 severity in pregnant patients. However, a recent publication mentioned a potentially increased risk of developing severe COVID-19 if the mothers were infected with the delta variant, compared to the alpha variant [34].

Preterm birth can lead to higher neonatal and infant mortality rates, especially at lower gestational ages [35]. Babies born prematurely face issues like the requirement of intensive care services after birth, the need for ongoing health and developmental support, a higher risk of long-term neurological impairment and developmental delay, and increased mortality rates [36] [37]. We found that preterm birth was not more common (9.7\% to $26.6 \%$ ) for pregnant women with COVID-19 positive status per se, a finding supported by various other studies as well as global preterm birth rate estimations [37] [38] [39].

However, pregnancies with symptomatic or severe COVID-19 symptoms had a higher likelihood of preterm birth, mainly iatrogenic [40]. Delahoy et al. reported preterm birth rates for symptomatic and asymptomatic pregnant women with COVID-19 infection at $23.1 \%$ and $8 \%$, respectively [41]. The dilemma to deliver prematurely stems from the need to balance between the benefit of improved maternal disease outcome and the risk of neonatal morbidity and mortality [42]. Still, it was inconclusive whether or not the delivery of infants showed significant improvement to the mothers' respiratory functions [43] [44] [45].

We reported that not more than half of the COVID-19 positive pregnant women underwent caesarean section. To date, no clear evidence has been found to support the indication of caesarean section for active COVID-19 infection [11] [46] [47]. Nonetheless, systematic reviews by Capobianco et al., Di Toro et al., and De Melo et al. have reported high rates of caesarean sections [11] [47] [48]. There are concerns on vertical transmission as vaginal delivery increases 
the risk of cross-infection, and caesarean sections are performed to minimize maternal exertion during labour and improve maternal respiratory function as per local guidelines or recommendations [46] [48].

A higher risk of caesarean births was reported for symptomatic pregnant women, a finding also supported by Vouga $\mathrm{M}$ et al. [33]. Furthermore, the risk of foetal distress may be increased during labour when the mother is symptomatic for COVID-19 [49] [50] [51] [52]. Possibly, the higher risk for foetal distress and potential maternal compromise led to higher rates of caesarean deliveries in symptomatic mothers, but a clear link between maternal COVID-19 severity and caesarean section was yet to be established. This finding implicated the value of a COVID-19 positive mother to deliver in an obstetrical unit where immediate access to emergency services can be provided if needed [40].

Pregnancies that were complicated with severe COVID-19 were at a higher risk of developing pre-eclampsia. Similar findings have been reported in a systematic review by Ghayda et al. [53]. It can be explained by the overexpression of proinflammatory cytokines (IL-6, TNF-alpha, IFN-gamma, etc.) during severe COVID-19, whose levels were also significantly raised in the preeclamptic placentas [54]. However, the coronavirus-provoked inflammatory cascade, better known as the "cytokine storm", was not found to influence the levels of specific pre-eclampsia-related angiogenic and anti-angiogenic markers like P1GF and sFLT-1 [55]. Nonetheless, placental inflammation serves as the linkage between COVID-19 and adverse foetal outcomes [56]. Another theory mentioned the downregulation of ACE2 as SARS-CoV-2 binds to it when entering host cells. With the lower level of ACE2, there is an increased plasmatic concentration of angiotensin II [57], whose primary function is to raise blood pressure through vasoconstriction [58].

While ICU admission rates remained low, both COVID-19 infections and their severity are associated with a higher risk of ICU admission. Consistent trends were observed by Huntley et al. and Elsaddig et al., which found that more pregnant women who were positive for COVID-19 required ICU admission compared to their non-infected counterparts [59] [60]. That being said, there is a possibility of a lower threshold for initiating treatment in pregnancies instead of more serious diseases [39] [59].

The most commonly encountered laboratory findings of COVID-19 infection in our reviewed studies include lymphopenia, elevated liver enzymes (ALT, AST), increased CRP, and procalcitonin, which can be useful as parameters to predict ICU admission [61]. We reported a small percentage of perinatal losses from our studies. Despite the low stillbirth rates, a positive COVID-19 diagnosis increases the risk for stillbirth by almost two-fold [28] [30] [62]. Studies examining the placental histopathology of COVID-19 infected mothers have found an increased frequency of vascular malperfusion and villitis, suggesting a plausible mechanism to explain the higher risk of stillbirth for COVID-19 mothers [63] [64] [65]. 


\section{Conclusions}

Despite the inclining rates of COVID-19 infection globally, most pregnant women expressed mild to moderate symptoms when infected with SARS-CoV-2. However, maternal pregestational comorbidity, in particular, an increased BMI, was shown to be associated with severe COVID-19 disease. Women with symptomatic COVID-19 had an increased risk for preterm birth compared to asymptomatic women, but the risk was not nearly as high as those with a severe or critical form of the COVID-19 disease. Another significant outcome was C-section, in which its incidence rate increased significantly, especially in the severe COVID-19 group. Other maternal outcomes, including maternal death, intrauterine death and infection, hypertensive disorders in pregnancy, stillbirth and post-partum haemorrhage, had lower incidence rates.

This review was consistent with previous studies on the increased preeclampsia, preterm birth, and caesarean delivery rates in COVID-19 positive pregnant women. This paper mainly contributes to identifying a potential link between COVID-19 severity and iatrogenic deliveries, including caesarean section, while establishing that COVID-19 itself may not be the chief offender in adverse maternal outcomes if the mother is asymptomatic or experiencing only mild COVID-19 symptoms.

This study has some limitations. We acknowledge that most of our study data are from a White or Middle-Eastern background, and thus, it may not be applicable to the Asian, south-east Asian, or Black communities. We also could not conduct a meta-analysis on the available data, which meant that we could not have pooled evidence to draw the conclusions on the summary estimate of the effect. While an effort was made to keep this review as updated as possible, it was understood that more research has to be done to maintain the validity of information as the COVID-19 situation keeps evolving and more papers emerge in the field. In addition, further studies are needed to evaluate the maternal management modality to induce a better prognosis among COVID-19 infected pregnant women in the future.

\section{Acknowledgements}

The authors would like to express their appreciation to the Monash University Library for providing permission to utilize the extensive resources, especially to get access to full-text articles and software (Endnote and Nvivo) for this systematic review.

\section{Conflicts of Interest}

There are no affiliations with or involvement in any organization or entity with any financial or non-financial interest in the subject matter or materials discussed in this review. The authors also declare no conflicts of interest regarding the publication of this paper. 


\section{References}

[1] Di Mascio, D., Khalil, A., Saccone, G., Rizzo, G., Buca, D., Liberati, M., et al. (2020) Outcome of Coronavirus Spectrum Infections (SARS, MERS, COVID-19) during Pregnancy: A Systematic Review and Meta-Analysis. American Journal of Obstetrics \& Gynecology MFM, 2, Article ID: 100107. https://doi.org/10.1016/j.ajogmf.2020.100107

[2] Ahn, D.G., Shin, H.J., Kim, M.H., Lee, S., Kim, H.S., Myoung, J., et al. (2020) Current Status of Epidemiology, Diagnosis, Therapeutics, and Vaccines for Novel Coronavirus Disease 2019 (COVID-19). Journal of Microbiology and Biotechnology, 30, 313-324. https://doi.org/10.4014/jmb.2003.03011

[3] Maleki Dana, P., Kolahdooz, F., Sadoughi, F., Moazzami, B., Chaichian, S. and Asemi, Z. (2020) COVID-19 and Pregnancy: A Review of Current Knowledge. Infezioni in Medicina, 28, 46-51.

[4] Mohamadian, M., Chiti, H., Shoghli, A., Biglari, S., Parsamanesh, N. and Esmaeilzadeh, A. (2021) COVID-19: Virology, Biology and Novel Laboratory Diagnosis. The Journal of Gene Medicine, 23, e3303.

https://doi.org/10.1002/jgm.3303

[5] Figueiro-Filho, E.A., Yudin, M. and Farine, D. (2020) COVID-19 during Pregnancy: An Overview of Maternal Characteristics, Clinical Symptoms, Maternal and Neonatal Outcomes of 10,996 Cases Described in 15 Countries. Journal of Perinatal Medicine, 48, 900-911. https://doi.org/10.1515/jpm-2020-0364

[6] Smith, V., Seo, D., Warty, R., Payne, O., Salih, M., Chin, K.L., et al. (2020) Maternal and Neonatal Outcomes Associated with COVID-19 Infection: A Systematic Review. PLoS ONE, 15, e0234187. https://doi.org/10.1371/journal.pone.0234187

[7] World Health Organisation (WHO) (2021) WHO Coronavirus (COVID-19) Dashboard. World Health Organisation, Geneva. https://covid19.who.int

[8] Lokken, E.M., Taylor, G.G., Huebner, E.M., Vanderhoeven, J., Hendrickson, S., Coler, B., et al. (2021) Higher Severe Acute Respiratory Syndrome Coronavirus 2 Infection Rate in Pregnant Patients. American Journal of Obstetrics and Gynecology, 225, 75.e1-16.

[9] Papapanou, M., Papaioannou, M., Petta, A., Routsi, E., Farmaki, M., Vlahos, N., et al. (2021) Maternal and Neonatal Characteristics and Outcomes of COVID-19 in Pregnancy: An Overview of Systematic Reviews. International Journal of Environmental Research and Public Health, 18, 596.

https://doi.org/10.3390/ijerph18020596

[10] Wong, Y.P., Khong, T.Y. and Tan, G.C. (2021) The Effects of COVID-19 on Placenta and Pregnancy: What Do We Know So Far? Diagnostics, 11, 13. https://doi.org/10.3390/diagnostics11010094

[11] Di Toro, F., Gjoka, M., Di Lorenzo, G., De Santo, D., De Seta, F., Maso, G., et al. (2021) Impact of COVID-19 on Maternal and Neonatal Outcomes: A Systematic Review and Meta-Analysis. Clinical Microbiology and Infection, 27, 36-46. https://doi.org/10.1016/j.cmi.2020.10.007

[12] Chi, J., Gong, W. and Gao, Q. (2021) Clinical Characteristics and Outcomes of Pregnant Women with COVID-19 and the Risk of Vertical Transmission: A Systematic Review. Archives of Gynecology and Obstetrics, 303, 337-345. https://doi.org/10.1007/s00404-020-05889-5

[13] Al-Matary, A., Almatari, F., Al-Matary, M., AlDhaefi, A., Alqahtani, M.H.S., Alhulaimi, E.A., et al. (2021) Clinical Outcomes of Maternal and Neonate with COVID-19 Infec- 
tion-Multicenter Study in Saudi Arabia. Journal of Infection and Public Health, 14, 702-708. https://doi.org/10.1016/j.jiph.2021.03.013

[14] Ayed, A., Embaireeg, A., Benawadh, A., Al-Fouzan, W., Hammoud, M., Al-Hathal, M., et al. (2020) Maternal and Perinatal Characteristics and Outcomes of Pregnancies Complicated with COVID-19 in Kuwait. BMC Pregnancy Childbirth, 20, 754. https://doi.org/10.1186/s12884-020-03461-2

[15] Crovetto, F., Crispi, F., Llurba, E., Pascal, R., Larroya, M., Trilla, C., et al. (2021) Impact of SARS-CoV-2 Infection on Pregnancy Outcomes: A Population-Based Study. Clinical Infectious Diseases: An Official Publication of the Infectious Diseases Society of America, ciab104.

[16] Cruz Melguizo, S., de la Cruz Conty, M.L., Carmona Payán, P., Abascal-Saiz, A., Pintando Recarte, P., González Rodríguez, L., et al. (2021) Pregnancy Outcomes and SARS-CoV-2 Infection: The Spanish Obstetric Emergency Group Study. Viruses, 13, 853. https://doi.org/10.3390/v13050853

[17] Haye, M.T., Cartes, G., Gutierrez, J., Ahumada, P., Krause, B., Merialdi, M., et al. (2021) Maternal and Perinatal Outcomes in Pregnant Women with Confirmed Severe and Mild COVID-19 at One Large Maternity Hospital in Chile. The Journal of Maternal-Fetal \& Neonatal Medicine, 1-6.

[18] Khoury, R., Bernstein, P.S., Debolt, C., Stone, J., Sutton, D.M., Simpson, L.L., et al. (2020) Characteristics and Outcomes of 241 Births to Women with Severe Acute Respiratory Syndrome Coronavirus 2 (SARS-CoV-2) Infection at Five New York City Medical Centers. Obstetrics \& Gynecology, 136, 273-282. https://doi.org/10.1097/AOG.0000000000004025

[19] Lokken, E.M., Huebner, E.M., Taylor, G.G., Hendrickson, S., Vanderhoeven, J., Kachikis, A., et al. (2021) Disease Severity, Pregnancy Outcomes, and Maternal Deaths among Pregnant Patients with Severe Acute Respiratory Syndrome Coronavirus 2 Infection in Washington State. American Journal of Obstetrics and Gynecology, 225, 77.e1-77.e14. https://doi.org/10.1016/j.ajog.2020.12.1221

[20] Martinez-Perez, O., Prats Rodriguez, P., Muner Hernandez, M., Encinas Pardilla, M.B., Perez Perez, N., Vila Hernandez, M.R., et al. (2021) The Association between SARS-CoV-2 Infection and Preterm Delivery: A Prospective Study with a Multivariable Analysis. BMC Pregnancy Childbirth, 21, 273.

https://doi.org/10.1186/s12884-021-03742-4

[21] Metz, T.D., Clifton, R.G., Hughes, B.L., Sandoval, G., Saade, G.R., Grobman, W.A., et al. (2021) Disease Severity and Perinatal Outcomes of Pregnant Patients with Coronavirus Disease 2019 (COVID-19). Obstetrics \& Gynecology, 137, 571-580. https://doi.org/10.1097/AOG.0000000000004339

[22] Saccone, G., Sen, C., Di Mascio, D., Galindo, A., Grunebaum, A., Yoshimatsu, J., et al. (2021) Maternal and Perinatal Outcomes of Pregnant Women with SARS-CoV-2 Infection. Ultrasound Obstetrics \& Gynecology, 57, 232-241. https://doi.org/10.1002/uog.23107

[23] Taya, R.M., Del Castillo, K.C., Arroyo, J.C.C. and Saenz, I.H.H. (2020) Sars-CoV-2 in the Second Half of Pregnancy: Maternal and Perinatal Outcomes. Revista Peruana de Ginecología y Obstetricia, 66, 6.

[24] Villar, J., Ariff, S., Gunier, R.B., Thiruvengadam, R., Rauch, S., Kholin, A., et al. (2021) Maternal and Neonatal Morbidity and Mortality among Pregnant Women with and without COVID-19 Infection: The INTERCOVID Multinational Cohort Study. JAMA Pediatrics, 175, 817-826.

https://doi.org/10.1001/jamapediatrics.2021.1050 
[25] Vousden, N., Bunch, K., Morris, E., Simpson, N., Gale, C., O’Brien, P., et al. (2021) The Incidence, Characteristics and Outcomes of Pregnant Women Hospitalized with Symptomatic and Asymptomatic SARS-CoV-2 Infection in the UK from March to September 2020: A National Cohort Study Using the UK Obstetric Surveillance System (UKOSS). PLoS ONE, 16, e0251123.

https://doi.org/10.1371/journal.pone.0251123

[26] Catalano, P.M. and Shankar, K. (2017) Obesity and Pregnancy: Mechanisms of Short Term and Long Term Adverse Consequences for Mother and Child. BMJ, 356, j1. https://doi.org/10.1136/bmj.j1

[27] Gaillard, R. (2015) Maternal Obesity during Pregnancy and Cardiovascular Development and Disease in the Offspring. European Journal of Epidemiology, 30, 1141-1152. https://doi.org/10.1007/s10654-015-0085-7

[28] Allotey, J., Stallings, E., Bonet, M., Yap, M., Chatterjee, S., Kew, T., et al. (2020) Clinical Manifestations, Risk Factors, and Maternal and Perinatal Outcomes of Coronavirus Disease 2019 in Pregnancy: Living Systematic Review and Meta-Analysis. The BMJ, 370, m3320. https://doi.org/10.1136/bmj.m3320

[29] Williamson, E.J., Walker, A.J., Bhaskaran, K., Bacon, S., Bates, C., Morton, C.E., et al. (2020) Factors Associated with COVID-19-Related Death Using OpenSAFELY. Nature, 584, 430-436. https://doi.org/10.1038/s41586-020-2521-4

[30] Gurol-Urganci, I., Jardine, J.E., Carroll, F., Draycott, T., Dunn, G., Fremeaux, A., et al. (2021) Maternal and Perinatal Outcomes of Pregnant Women with SARS-CoV-2 Infection at the Time of Birth in England: National Cohort Study. American Journal of Obstetrics and Gynecology. https://doi.org/10.1016/j.ajog.2021.05.016

[31] Singh, V., Choudhary, A., Datta, M.R. and Ray, A. (2021) Maternal and Neonatal Outcomes of COVID-19 in Pregnancy: A Single-Centre Observational Study. $\mathrm{Cu}$ reus, 13, 10. https://doi.org/10.7759/cureus.13184

[32] Nayak, A.H., Kapote, D.S., Fonseca, M., Chavan, N., Mayekar, R., Sarmalkar, M., et al. (2020) Impact of the Coronavirus Infection in Pregnancy: A Preliminary Study of 141 Patients. The Journal of Obstetrics and Gynecology of India, 70, 256-261. https://doi.org/10.1007/s13224-020-01335-3

[33] Vouga, M., Favre, G., Martinez-Perez, O., Pomar, L., Acebal, L.F., Abascal-Saiz, A., et al. (2021) Maternal Outcomes and Risk Factors for COVID-19 Severity among Pregnant Women. Scientific Reports, 11, Article No. 13898. https://doi.org/10.1038/s41598-021-92357-y

[34] Vousden, N., Ramakrishnan, R., Bunch, K., Morris, E., Simpson, N., Gale, C., et al. (2021) Impact of SARS-CoV-2 Variant on the Severity of Maternal Infection and Perinatal Outcomes: Data from the UK Obstetric Surveillance System National Cohort. https://doi.org/10.1101/2021.07.22.21261000

[35] Royal College of Obstetricians and Gynaecology (RCOG) (2015) Preterm Labour and Birth.

https://www.nice.org.uk/guidance/ng25/resources/preterm-labour-and-birth-pdf-1 $\underline{837333576645}$

[36] Institute of Medicine (US) Committee on Understanding Premature Birth and Assuring Healthy Outcomes (2007) Preterm Birth: Causes, Consequences, and Prevention. National Academies Press (US), Washington DC.

[37] Chawanpaiboon, S., Vogel, J.P., Moller, A.B., Lumbiganon, P., Petzold, M., Hogan, D., et al. (2019) Global, Regional, and National Estimates of Levels of Preterm Birth in 2014: A Systematic Review and Modelling Analysis. The Lancet Glob Health, 7, e37-e46. https://doi.org/10.1016/S2214-109X(18)30451-0 
[38] Cardona-Pérez, J.A., Villegas-Mota, I., Helguera-Repetto, A.C., Acevedo-Gallegos, S., Rodríguez-Bosch, M., Aguinaga-Ríos, M., et al. (2021) Prevalence, Clinical Features, and Outcomes of SARS-CoV-2 Infection in Pregnant Women with or without Mild/Moderate Symptoms: Results from Universal Screening in a Tertiary Care Center in Mexico City, Mexico. PLoS ONE, 16, e0249584.

https://doi.org/10.1371/journal.pone.0249584

[39] Donati, S., Maraschini, A., Lega, I., D’Aloja, P., Sampaolo, L., Salvatore, M.A., et al. (2020) Coronavirus and Birth in Italy: Results of a National Population-Based Cohort Study. Annali dell Istituto Superiore di Sanita, 56, 378-389.

https://doi.org/10.1101/2020.06.11.20128652

[40] Royal College of Obstetricians and Gynaecologists (2021) Coronavirus (COVID-19) Infection in Pregnancy.

https://www.rcog.org.uk/globalassets/documents/guidelines/2021-08-25-coronaviru s-covid-19-infection-in-pregnancy-v14.pdf

[41] Delahoy, M.J., Whitaker, M., O’Halloran, A., Chai, S.J., Kirley, P.D., Alden, N., et al. (2020) Characteristics and Maternal and Birth Outcomes of Hospitalized Pregnant Women with Laboratory-Confirmed COVID-19-COVID-NET, 13 States, March 1-August 22, 2020. MMWR Morbidity and Mortality Weekly Report, 69, 1347-1354. https://doi.org/10.1101/2020.06.11.20128652

[42] Fontanella, F., Hannes, S., Keating, N., Martyn, F., Browne, I., Briet, J., et al. (2020) COVID-19 Infection during the Third Trimester of Pregnancy: Current Clinical Dilemmas. European Journal of Obstetrics \& Gynecology and Reproductive Biology, 251, 268-271. https://doi.org/10.1016/j.ejogrb.2020.05.053

[43] Mabie, W.C., Barton, J.R. and Sibai, B.M. (1992) Adult Respiratory Distress Syndrome in Pregnancy. American Journal of Obstetrics and Gynecology, 167, 950-957. https://doi.org/10.1016/S0002-9378(12)80018-4

[44] Lam, C.M., Wong, S.F., Leung, T.N., Chow, K.M., Yu, W.C., Wong, T.Y., et al. (2004) A Case-Controlled Study Comparing Clinical Course and Outcomes of Pregnant and Non-Pregnant Women with Severe Acute Respiratory Syndrome. BJOG, 111, 771-774. https://doi.org/10.1111/j.1471-0528.2004.00199.x

[45] Lapinsky, S.E., Rojas-Suarez, J.A., Crozier, T.M., Vasquez, D.N., Barrett, N., Austin, K., et al. (2015) Mechanical Ventilation in Critically-Ill Pregnant Women: A Case Series. International Journal of Obstetric Anesthesia, 24, 323-328.

https://doi.org/10.1016/j.ijoa.2015.06.009

[46] Chamseddine, R.S., Wahbeh, F., Chervenak, F., Salomon, L.J., Ahmed, B. and Rafii, A. (2020) Pregnancy and Neonatal Outcomes in SARS-CoV-2 Infection: A Systematic Review. Journal of Pregnancy, 2020, Article ID: 4592450. https://doi.org/10.1155/2020/4592450

[47] Capobianco, G., Saderi, L., Aliberti, S., Mondoni, M., Piana, A., Dessole, F., et al. (2020) COVID-19 in Pregnant Women: A Systematic Review and Meta-Analysis. European Journal of Obstetrics and Gynecology and Reproductive Biology, 252, 543-558. https://doi.org/10.1016/j.ejogrb.2020.07.006

[48] de Melo, G.C. and de Araújo, K.C.G.M. (2020) COVID-19 Infection in Pregnant Women, Preterm Delivery, Birth Weight, and Vertical Transmission: A Systematic Review and Meta-Analysis. Cadernos de Saude Publica, 36, e00087320. https://doi.org/10.1590/0102-311x00087320

[49] Chen, H., Guo, J., Wang, C., Luo, F., Yu, X., Zhang, W., et al. (2020) Clinical Characteristics and Intrauterine Vertical Transmission Potential of COVID-19 Infection in Nine Pregnant Women: A Retrospective Review of Medical Records. The 
Lancet, 395, 809-815. https://doi.org/10.1016/S0140-6736(20)30360-3

[50] Zhu, H., Wang, L., Fang, C., Peng, S., Zhang, L., Chang, G., et al. (2020) Clinical Analysis of 10 Neonates Born to Mothers with 2019-nCoV Pneumonia. Translational Pediatrics, 9, 51-60. https://doi.org/10.21037/tp.2020.02.06

[51] Zimmermann, P. and Curtis, N. (2020) COVID-19 in Children, Pregnancy and Neonates: A Review of Epidemiologic and Clinical Features. The Pediatric Infectious Disease Journal, 39, 469-477. https://doi.org/10.1097/INF.0000000000002700

[52] Yang, Z., Wang, M., Zhu, Z. and Liu, Y. (2020) Coronavirus Disease 2019 (COVID-19) and Pregnancy: A Systematic Review. Journal of Maternal-Fetal and Neonatal Medicine, 1-4. https://doi.org/10.1080/14767058.2020.1759541

[53] Ghayda, R.A., Li, H., Lee, K.H., Lee, H.W., Hong, S.H., Kwak, M., et al. (2020) COVID-19 and Adverse Pregnancy Outcome: A Systematic Review of 104 Cases. Journal of Clinical Medicine, 9, 3441. https://doi.org/10.3390/jcm9113441

[54] Todros, T., Masturzo, B. and De Francia, S. (2020) COVID-19 Infection: ACE2, Pregnancy and Preeclampsia. European Journal of Obstetrics \& Gynecology and Reproductive Biology, 253, 330. https://doi.org/10.1016/j.ejogrb.2020.08.007

[55] Mendoza, M., Garcia-Ruiz, I., Maiz, N., Rodo, C., Garcia-Manau, P., Serrano, B., et al. (2020) Pre-Eclampsia-Like Syndrome Induced by Severe COVID-19: A Prospective Observational Study. BJOG: An International Journal of Obstetrics \& Gynaecology, 127, 1374-1380. https://doi.org/10.1111/1471-0528.16339

[56] Nadeau-Vallée, M., Obari, D., Palacios, J., Brien, M., Duval, C., Chemtob, S., et al. (2016) Sterile Inflammation and Pregnancy Complications: A Review. Reproduction, 152, R277-R292. https://doi.org/10.1530/REP-16-0453

[57] Silhol, F., Sarlon, G., Deharo, J.C. and Vaïsse, B. (2020) Downregulation of ACE2 Induces Overstimulation of the Renin-Angiotensin System in COVID-19: Should We Block the Renin-Angiotensin System? Hypertension Research, 43, 854-856. https://doi.org/10.1038/s41440-020-0476-3

[58] Fyhrquist, F., Metsärinne, K. and Tikkanen, I. (1995) Role of Angiotensin II in Blood Pressure Regulation and in the Pathophysiology of Cardiovascular Disorders. Journal of Human Hypertension, 9, S19-S24.

[59] Elsaddig, M. and Khalil, A. (2021) Effects of the COVID Pandemic on Pregnancy Outcomes. Best Practice \& Research: Clinical Obstetrics \& Gynaecology, 73, 125-136. https://doi.org/10.1016/j.bpobgyn.2021.03.004

[60] Huntley, B.J.F., Mulder, I.A., Di Mascio, D., Vintzileos, W.S., Vintzileos, A.M., Berghella, V., et al. (2021) Adverse Pregnancy Outcomes among Individuals with and without Severe Acute Respiratory Syndrome Coronavirus 2 (SARS-CoV-2): A Systematic Review and Meta-Analysis. Obstetrics \& Gynecology, 137, 585-596. https://doi.org/10.1097/AOG.0000000000004320

[61] Zhang, J.J.Y., Lee, K.S., Ang, L.W., Leo, Y.S. and Young, B.E. (2020) Risk Factors for Severe Disease and Efficacy of Treatment in Patients Infected with COVID-19: A Systematic Review, Meta-Analysis, and Meta-Regression Analysis. Clinical Infectious Diseases, 71, 2199-2206. https://doi.org/10.1093/cid/ciaa576

[62] Wei, S.Q., Bilodeau-Bertrand, M., Liu, S. and Auger, N. (2021) The Impact of COVID-19 on Pregnancy Outcomes: A Systematic Review and Meta-Analysis. CMAJ, 193, E540-E548. https://doi.org/10.1503/cmaj.202604

[63] Patberg, E.T., Adams, T., Rekawek, P., Vahanian, S.A., Akerman, M., Hernandez, A., et al. (2021) Coronavirus Disease 2019 Infection and Placental Histopathology in 
Women Delivering at Term. American Journal of Obstetrics and Gynecology, 224, 382.e1-382.e18. https://doi.org/10.1016/j.ajog.2020.10.020

[64] Sharps, M.C., Hayes, D.J.L., Lee, S., Zou, Z., Brady, C.A., Almoghrabi, Y., et al. (2020) A Structured Review of Placental Morphology and Histopathological Lesions Associated with SARS-CoV-2 Infection. Placenta, 101, 13-29. https://doi.org/10.1016/j.placenta.2020.08.018

[65] Jaiswal, N., Puri, M., Agarwal, K., Singh, S., Yadav, R., Tiwary, N., et al. (2021) COVID-19 as an Independent Risk Factor for Subclinical Placental Dysfunction. European Journal of Obstetrics \& Gynecology and Reproductive Biology, 259, 7-11. https://doi.org/10.1016/j.ejogrb.2021.01.049 


\section{List of Abbreviation}

\begin{tabular}{|c|c|}
\hline Abbreviation & Representation \\
\hline 2019-nCoV & 2019 Novel Coronavirus \\
\hline $95 \% \mathrm{CI}$ & 95\% Confidence Interval \\
\hline $\mathrm{aOR}$ & Adjusted Odds Ratio \\
\hline ACE2 & Angiotensin Converting Enzyme 2 \\
\hline ALT & Alanine Aminotransferase \\
\hline AST & Aspartate Aminotransferase \\
\hline BMI & Body Mass Index \\
\hline COVID-19 & Coronavirus Disease 19 \\
\hline CPAP & Continuous Positive Airway Pressure \\
\hline CRP & C-Reactive Protein \\
\hline ECMO & Extracorporeal Membrane Oxygen \\
\hline Emtree & Embase Subject Headings \\
\hline HELLP & Haemolysis, Elevated Liver enzyme and Low Platelet Syndrome \\
\hline ICU & Intensive Care Unit \\
\hline IFN-gamma & Interferon Gamma \\
\hline $\operatorname{Ig} \mathrm{A}$ & Immunoglobulin A \\
\hline IgG & Immunoglobulin $\mathrm{G}$ \\
\hline $\operatorname{IgM}$ & Immunoglobulin $\mathrm{M}$ \\
\hline IL-6 & Interleukin-6 \\
\hline LMWH & Low Molecular Weight Heparin \\
\hline MERS & Middle East Respiratory Syndrome \\
\hline MERS-CoV & Middle East Respiratory Syndrome Coronavirus \\
\hline $\mathrm{MeSH}$ & Medical Subject Headings \\
\hline $\mathrm{NICU}$ & Neonatal Intensive Care Unit \\
\hline NOS & Newcastle-Ottawa Scale \\
\hline OR & Odds ratio \\
\hline PECO & Population, Exposure, Comparison/Control, Outcome \\
\hline PlGF & Placental Growth Factor \\
\hline PPROM & Preterm prelabour rupture of membranes \\
\hline PRISMA & Preferred Reporting Items for Systematic Reviews and Meta-Analyses \\
\hline RT-PCR & Real-time polymerase chain reaction \\
\hline $\mathrm{RR}$ & Relative risk \\
\hline SARS & Severe Acute Respiratory Syndrome \\
\hline SARS-CoV-1 & Severe Acute Respiratory Syndrome Coronavirus 1 \\
\hline SARS-CoV-2 & Severe Acute Respiratory Syndrome Coronavirus 2 \\
\hline sFLT-1 & Soluble Fms-Like Tyrosine Kinase-1 \\
\hline TNF-alpha & Tumour Necrosis Factor Alpha \\
\hline WHO & World Health Organisation \\
\hline
\end{tabular}

